\title{
O histórico da segurança humana e o (des)encontro das agendas de desenvolvimento \\ e segurança
}

\section{The history of human security and the (mis) match of the development and security agendas}

\author{
DOI: $10.21530 /$ ci.v12n3.2017.676
}

Raquel Maria de Almeida Rocha ${ }^{1}$

\section{Resumo}

O presente artigo busca reconstruir a trajetória da segurança humana no Relatório de Desenvolvimento Humano (RDH) do Programa de Desenvolvimento das Nações Unidas (PNUD) de 1994 e no Relatório da Comissão Internacional sobre Intervenção e Soberania Estatal (CIISE) de 2001. Pretendemos com isso demonstrar que existe pouco diálogo e contribuição do primeiro com o segundo. Para tanto, traçaremos o histórico do conceito de segurança humana, focando nos relatórios mencionados, a fim de evidenciar a forma pela qual as agendas de desenvolvimento e de segurança possuem baixo nível de debate, diálogo e contribuição entre si. Nossa metodologia inclui revisão bibliográfica e entrevistas, além de análise de documentos e relatórios do sistema ONU e do CIISE para construção de process tracing.

Palavras-chave: Segurança humana; Desenvolvimento; Relatório de Desenvolvimento Humano (RDH); Relatório da Comissão Internacional sobre Intervenção e Soberania Estatal (CIISE).

\begin{abstract}
The article seeks to reconstruct the trajectory of human security on the Human Development Report (HDR) from the United Nations Development Program (UNDP) of 1994 and on the International Commission on Intervention and State Sovereignty (ICISS) Report of 2001. We intent to demonstrate that there is little dialogue and contribution between the two. For that, we trace the history of the concept of human security, focusing on the mentioned reports,

1 Departamento de Relações Internacionais da Escola Superior de Propaganda e Marketing, São Paulo/SP, Brasil. E-mail: raquel.maria.rocha@espm.br

Artigo submetido em 27/05/2017 e aprovado em 03/11/2017.
\end{abstract}


seeking to evidence the way by which the agendas of development and security have a low level of debate, dialogue and contribution amongst them. Out methodology includes literature review, interviews and analyses of documents and reports of the UN system and the ICISS for process tracing.

Keywords: Human security; Development; Human Development Report; International Commission on Intervention and State Sovereignty (ICISS).

\section{Introdução}

A segurança humana, mesmo que controversa, foi incorporada por Estados, organizações internacionais, regionais e não governamentais. O debate em relação a sua relevância, significado e definição é constante, mas já está incorporado nos círculos acadêmicos e políticos ${ }^{2}$. Os valores e ideais embutidos nele estão presentes na carta constitutiva das Nações Unidas de 1945 e nos demais instrumentos do direito internacional que se preocupam com uma concepção da segurança focada nas pessoas 3 . No entanto, a expressão “segurança humana” surge apenas no início dos anos de 1990 como um dispositivo intelectual e instrumento de advocacy nas relações internacionais, unindo preocupações sobre proteção, direitos e bem-estar individual. A segurança humana engloba a ideia de que a segurança vai além do simples conceito da garantia da segurança física, no sentido tradicional, ao incorporar que as pessoas também devem ter garantida uma "segurança social”. Além de buscar identificar ameaças, evitá-las e mitigar seus efeitos sempre que possível, como as demais concepções de segurança.

Tadjbakhsh e Chenoy (2007, p. 27) fazem uma divisão cronológica de três grandes estágios para a construção do conceito de segurança humana4. Primeiramente, o termo foi utilizado no Relatório de Desenvolvimento Humano (RDH) do Programa das Nações Unidas para o Desenvolvimento (PNUD) ${ }^{5}$, no

2 Ver, e.g, PARIS, 2001; MCRAE, HUBERT, 2001; HAMPSON et al, 2002; BUZAN, 2004; MACFARLANE, KHONG, 2006; OWEN, 2008; KRAUSE, 2014; MARTIN; OWEN, 2015.

3 Como por exemplo a Declaração Universal de Direitos Humanos de 1948 e as convenções associadas de 1966, Convenção para a Prevenção e a Repressão do Crime de Genocídio de 1948, Convenção relativa ao Estatuto do Refugiado de 1951, Convenção sobre a Eliminação de todas as formas de Discriminação contra a Mulher de 1979, Convenção sobre os Direitos da Criança de 1989, dentre outros.

4 Martin e Owen (2010) falam em duas gerações, pois unificam os dois primeiros "estágios”.

5 Embora a expressão seja mencionada anteriormente por Boutros-Ghali no relatório Uma Agenda para a Paz, em 1992, e posteriormente seja citada cinco vezes no relatório de 1993 para expressar o "desenvolvimento centrado nas pessoas”, é somente no RDH de 1994 que ela vai ser formalmente definida. 
qual a segurança humana foi descrita como liberdade do medo (freedom from fear) e liberdade de necessidades (freedom from want). A definição conta com a contribuição de Estados-membros, órgãos e agências internas, e também de figuras políticas e acadêmicas na liderança e modelagem da discussão. O relatório tentou aproveitar as reflexões do pós-Guerra Fria, juntamente com novos temas e atores que emergiam do período. É necessário lembrar que, nesse período, os temas de segurança eram restritos e enquadrados em um debate Leste-Oeste. Enquanto a questão do desenvolvimento era Norte-Sul.

Nef (1999) ressalta que, nesse período, a segurança e o desenvolvimento não mais eram vistos através de perspectivas de soma zero, mas sim como ganho e perda quando colocados em conjunto, principalmente quando pensamos nas ameaças transfronteiriças como pobreza ou epidemias, por exemplo. Logo, altos níveis de segurança levam ao desenvolvimento econômico, o que promove segurança e, por conseguinte, altos níveis de desenvolvimento, o que gera segurança e promove desenvolvimento, e assim em diante. A segurança humana é fundamentada no desenvolvimento humano. Porém, o RDH foi recebido com ceticismo pelo G77, pois os Estados temiam que o conceito levaria a violações da soberania estatal, o que fez com que a segurança humana não fosse adotada durante a Cúpula Mundial para o Desenvolvimento Social de Copenhague em 1995.

Mesmo assim, a Rede de Segurança Humana (RSH) formada por uma coalizão de 13 países $^{6}$, liderados pelo Canadá, uniu esforços para campanhas de advocacy que levaram à assinatura da Convenção de Ottawa em 1997 e do Estatuto de Roma em 1998. A RSH se organiza em torno da temática da Convenção de Ottawa que se formaliza em 1999. Além disso, a RSH liderou encontros ministeriais que discutiam questões como direitos humanos, prevenção de conflitos e HIV/AIDS. Em 2000, é criado - por iniciativa japonesa - o Fundo das Nações Unidas para a Segurança Humana (FNUSH), a fim de concretizar e operacionalizar o conceito, ao financiar projetos relacionados à construção da paz, à restauração pós-conflito, às abordagens da pobreza crônica, à redução de risco de desastre, ao tráfico humano e à segurança alimentar, buscando traduzi-lo em atividades operacionais que proporcionem benefícios sustentáveis às pessoas e comunidades que tenham sua sobrevivência, dignidade e sustento ameaçados; além de empoderar os indivíduos

6 Áustria, Canadá, Chile, Costa Rica, Grécia, Irlanda, Jordânia, Mali, Holanda, Noruega, Suíça, Eslovênia e Tailândia, além da África do Sul como observador. O Japão foi convidado para participar desde o início da rede, mas declinou em duas ocasiões devido à ênfase na intervenção humanitária e à reserva fundamental japonesa em usar a força sem a autorização do Conselho de Segurança da ONU (TAKASU, 2015: p. 245). 
para aumentar sua resiliência. O primeiro estágio é um período de aplicação prática da segurança humana.

O segundo estágio ocorreu entre 2001 e 2003. O conceito é recuperado no debate sobre a "Responsabilidade de Proteger” dentro do Relatório da Comissão Internacional sobre Intervenção e Soberania Estatal (CIISE), liderada e patrocinada pelo governo canadense, e também nas discussões sobre a "responsabilidade por desenvolvimento" iniciadas pelo governo japonês na Comissão de Segurança Humana (CSH). Aqui, o conceito aparece embebido em preocupações da agenda estatal e da agenda da segurança tradicional, principalmente da leitura realizada pelo governo canadense do que seria a segurança humana - focada largamente na segurança física das pessoas. O CIISE conta com a participação de acadêmicos e Estados patrocinadores. Já o terceiro estágio vai dos anos de 2004 a 2005, quando a segurança humana passa a ser o tema de agendas de reforma no sistema das Nações Unidas e em organismos regionais como a União Europeia.

Grande parte da literatura de relações internacionais situa segurança humana no debate de ampliação dos estudos de segurança internacional. Contudo, sua origem é decorrente de debates dos economistas desenvolvimentistas ${ }^{7}$ sobre como humanizar a economia e lidar com as novas ameaças ao indivíduo, especificamente no RDH do PNUD de 1994. A princípio, a ideia da segurança humana encontrou resistência por parte de acadêmicos de segurança e de alguns Estados e foi somente em 2001, no Relatório do CIISE, que a primeira “contraproposta” ou redefinição da segurança humana ocorreu, na forma da responsabilidade de proteger, reforçando ainda mais os receios sobre violações da soberania estatal. Enquanto na dimensão do desenvolvimento temos o RDH como marco inicial para definir a segurança humana, é possível argumentar que o marco inicial desse debate no âmbito da agenda de segurança é o CIISE. Até a aprovação do relatório que propõe o conceito de Responsabilidade de Proteger, existiam somente algumas

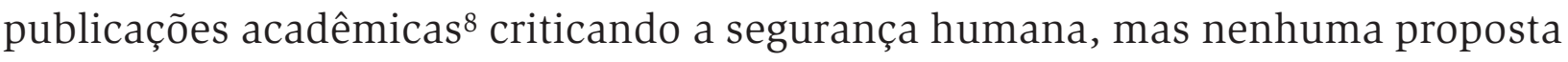
ou aplicação concreta da abordagem.

Este artigo pretende demonstrar que há pouco diálogo entre o RDH do PNUD de 1994 e o CIISE de 2001 no que tange a construção da abordagem da segurança humana, o que gera impactos tanto em termos de reflexão quanto na aplicabilidade

7 Economistas desenvolvimentistas são aqueles que não se contentam em definir desenvolvimento em termos de crescimento e medições de agregação nacional, e passam a focar na mensuração do bem-estar humano e nas formas através das quais se afeririam melhoras de bem-estar na vida das pessoas.

8 Ver e.g. (MCRAE, HUBERT, 2001). 
do conceito. Para tanto, traçaremos o histórico do conceito de segurança humana, buscando evidenciar o nível baixo de debate, diálogo e contribuição entre as agendas de desenvolvimento e de segurança. Nossa metodologia inclui revisão bibliográfica e entrevistas com funcionários do PNUD, além da análise de documentos e relatórios do sistema ONU e do CIISE para elaboração de process tracing 9 . Vale notar que o artigo não está baseado em uma hipótese, utilizamos como recurso a hermenêutica ao invés do positivismo cientifico. A intenção aqui não é confirmar ou falsear uma suposição, mas sim reconstruir a trajetória de uma ideia à fim de lançar luz em uma intersecção pouco explorada, que gera consequências para os rumos tanto da agenda de segurança quanto da de desenvolvimento. Para isso, este trabalho está estruturado em quatro partes: introdução, apresentação da construção do Relatório do PNUD, apresentação da construção do Relatório do CIISE e conclusões.

\section{A segurança humana nos anos de 1990}

Conforme apontado na introdução, a segurança humana é definida de forma contundente no RDH de 1994 do PNUD. O PNUD é um programa do sistema ONU, criado em 1965 para realizar atividades em países em desenvolvimento por meio da cooperação técnica multilateral e nasce da fusão do Programa Ampliado de Assistência Técnica das Nações Unidas de 1949 e do Fundo Especial das Nações Unidas de 1959. Suas atividades buscam o desenvolvimento tanto nos setores econômicos quanto nos sociais e desenvolvem projetos com os setores público e privado ao incentivar uma gestão responsável em todos os níveis da sociedade, buscando conquistar o desenvolvimento humano sustentável (UNIC, 2009).

Alocado no PNUD, está o Escritório do Relatório do Desenvolvimento Humano (ERDH), sediado em Nova Iorque. Possui a missão de avançar o desenvolvimento humano e o objetivo de contribuir a favor da expansão das oportunidades, escolhas e liberdades (UNDP, 2015). O escritório busca promover novas ideias, mudanças práticas de política e desafiar de forma construtiva políticas que dificultem o desenvolvimento humano. Para isso, o Escritório publica, desde 1990 e 1992 respectivamente, o Relatório do Desenvolvimento Humano e os Relatórios Nacionais

9 Entendemos process tracing como uma ferramenta qualitativa de análise interna de um caso que visa explanar um fenômeno social ao buscar identificar padrões e sequências através da reconstrução do processo de construção do fenômeno. 
e Regionais do Desenvolvimento Humano. O primeiro monitora o "progresso da humanidade” através de classificações de países, de acordo com o Índice de Desenvolvimento Humano (IDH), dentre outros (UL HAQ, 1995), enquanto o segundo é uma "caixa de ferramentas" (UNDP, 2015) que propõe ações passo a passo para que um país conquiste o desenvolvimento humano. Como seu foco é na pesquisa e publicação, possui autonomia, conforme explanaremos abaixo.

O primeiro RDH, lançado em 24 de maio de 1990, explora a relação entre crescimento econômico e desenvolvimento humano e tem o foco de aumentar as opções disponíveis para as pessoas ao invés de focar somente em quanto a nação está produzindo, segundo Ul Haq (1995). O texto estabelece que as pessoas são a real riqueza de uma nação, premissa que passa a guiar os demais relatórios. A parceria de Ul Haq com Sem fez com que o conceito do desenvolvimento humano ganhasse maior robustez teórica ${ }^{10}$, além de contar com diversidade de dados empíricos e uma abordagem inovadora para medir desenvolvimento. Dessa forma, o RDH acarretou largo impacto no pensamento sobre desenvolvimento ao redor do globo.

O desenvolvimento humano, para Amartya Sen (1999), pode ser visto como um processo de expansão das reais liberdades que os indivíduos gozam e afirma que focar nas liberdades do ser humano contrasta com visões mais restritas do desenvolvimento, como identificar desenvolvimento através desenvolvimento através da mensuração do crescimento do produto interno bruto (PIB) ou com aumento de rendas pessoais, industrialização, avanço tecnológico, industrialização ou modernização social. Aumentos de renda ou PIB podem ser meios significativos para que indivíduos expandam as suas liberdades enquanto membros da sociedade, mas existem outros determinantes destas liberdades como arranjos econômicos — tais como acesso à educação e saúde - bem como direitos políticos e civis por exemplo, ter a liberdade para participar em discussões públicas. Da mesma forma, o progresso tecnológico, industrial ou modernização social podem contribuir substancialmente na expansão da liberdade humana, mas estes também podem sofrer influências. Ver desenvolvimento em termos de expansão de liberdades substantivas direciona atenção para os fins que fazem o desenvolvimento importante, ao invés de alguns meios terem meramente um papel proeminente no processo (SEN, 1999).

10 Sen redigiu em co-autoria com Sudhir Anand o Human Development Index: Methodology and Measurement, em 1992, como background paper e, em 1993,o texto entra como parte do RDH (UL HAQ 1995). 
Em termos institucionais, o PNUD, dentre outras organizações, exerceu um papel significativo neste processo de reconceptualização, especialmente no desenvolvimento de medidas de desenvolvimento humano e taxa de desempenho, encorajando recipientes de assistência de desenvolvimento a focar na distribuição de renda, qualidade de vida e conquista de necessidades básicas, o que também possuiu um efeito de transbordo uma vez que influencia políticas e práticas de agências e seus maiores doadores. O RDH seria, então, o produto anual de um esforço coletivo do ERDH, sob a orientação do diretor e através de pesquisa, dados estatísticos, comunicação, equipe de publicação e um time de apoio responsável pelo Relatório Nacional e Regional. A pesquisa e redação do mesmo é então um trabalho conjunto do time administrativo do ERDH, do grupo de conselheiros eminentes e do diretor do ERDH, além de contar com contribuições de especialistas externos (UNDP, 2011), todos identificados no início de cada um dos relatórios na seção dos agradecimentos.

Os background papers são documentos produzidos pelos assessores do ERDH, com cerca de 5 a 10 páginas, contendo uma primeira proposta do que seria um dos capítulos do RDH (JAHAN, 2016), através de argumentos baseados em pesquisa, evidências e dados que devem respeitar um padrão de qualidade em termos de comparações globais ou regionais e da cobertura em termos de países, população global coberta etc. Já o Painel de Assessores Externos é composto por especialistas e pioneiros em desenvolvimento humano, buscando equilíbrio geográfico e de gênero, indicados pela diretoria do ERDH para o administrador do PNUD, que detém a última palavra (MUKHOPADHYAY, 2016).

A estrutura tem sido razoavelmente a mesma ao longo dos anos, variando em tamanho e composição, de acordo com as necessidades para a temática e os recursos disponíveis no escritório para determinado ano. Tal multidisciplinaridade permite que o time tenha diferentes compreensões sobre prioridades de políticas específicas. Assim, seu objetivo, de forma mais ampla, é desenvolver análises e opções de posições de políticas que sejam mais consistentes com a abordagem das capacidades do desenvolvimento humano. Todos os RDH tentam realizar inovações/ recomendações analíticas, empíricas e de políticas que possam enriquecer o debate para além do foco do tema anual.

Jahan (2016) ainda afirma que existe um processo de consultas com diversos stakeholders como o Conselho Executivo, o Painel de Assessores, acadêmicos e pesquisadores, bem como outras agências do sistema ONU, mas, que mesmo ao realizar tais consultas com grupos diversos, existe independência editorial - 
garantida pela Assembleia-Geral ${ }^{11}$ e pelo Conselho Executivo do PNUD. Dessa forma, pode ou não serem incluídas sugestões colocadas por tais representações, pois não é necessária autorização para a publicação do conteúdo e nenhuma das partes consultadas participa do processo de redação do relatório (JAHAN, 2016). Assim, as análises e recomendações de políticas estabelecidas nos RDHs não necessariamente refletem as visões oficiais do PNUD, de seu Conselho Executivo ou do sistema ONU como um todo.

É relevante compreender o processo de elaboração do RDH para que fique clara a origem desse discurso inicial da segurança humana, pois toda discussão subsequente sobre o termo tem tal ponto de origem. E também porque a literatura das relações internacionais acaba por fazer uma leitura de que essa foi uma contribuição praticamente exclusiva do sistema ONU, ao afirmar que a organização serviu de incubadora para aspectos chave do pensamento da segurança humana (MACFARLANE; KHONG, 2006; MARTIN; OWEN, 2010).

Contudo, é possível afirmar que a variável determinante para a definição inicial do termo foi a parceria com acadêmicos - há um esforço de pesquisa acadêmica, de investigação e compilação de dados, revisão de pares e propostas de políticas para os Estados-membros. Isso fica evidenciado na liberdade editorial que é concedida ao Relatório, na composição do corpo de funcionários e autonomia do ERDH com relação à estrutura do PNUD, órgão que o abriga (além do sistema como um todo), desde os primórdios da publicação.

Por mais que o sistema ONU possa ser considerado um ambiente propício para o surgimento de novos termos, onde atores diversos se unem para buscar soluções para ameaças à paz e segurança internacional, o Relatório é uma atividade majoritariamente analítica e não possui envolvimento algum por parte dos Estadosmembros, ao menos em nível institucional. O atual diretor do ERDH, Selim Jaham (2016), afirma que os temas são definidos pela equipe e somente depois ocorrem as consultas entre as agências do próprio sistema e Estados-membros na busca de opiniões e sugestões.

O Relatório de 1994 é o primeiro onde a segurança humana é definida, conforme previamente citado, e é o que populariza a abordagem, pois essa

11 Sua autonomia editorial é garantida através de uma resolução especial da AGNU — A/RES/57/264 —, que reconhece o RDH como um exercício intelectual independente e importante ferramenta em trazer atenção sobre desenvolvimento humano ao redor do globo (UN, 2003). Ademais, Haq ressalta em seu livro Reflections on Human Development que a independência intelectual e integridade profissional inicial dos relatórios somente ocorreram porque William H. Draper III, diretor Administrativo do PNUD (1986-93) acreditou no projeto e resistiu à pressão internacional(UL HAQ 1995). 
segue sendo a definição mais citada (PARIS, 2001; MACFARLANE; KHONG, 2006; NEWMAN, 2010). Ele possui 226 páginas e foi realizado com o objetivo de influenciar o diálogo de cooperação para o desenvolvimento entre Estados-membros e agências e programas do sistema ONU. Busca tratar do que chama de "crise silenciosa”, uma crise de subdesenvolvimento, pobreza, pressão e degradação do meio ambiente (UNDP, 1994: p. iii). Além disso, propôs uma agenda para a Cúpula Mundial para Desenvolvimento Social, que ocorreu em Copenhague em 1995, reconhecendo que a solução para tal crise deveria partir de um significativo investimento no desenvolvimento humano e que os papeis das Nações Unidas e do próprio PNUD deveriam ser fortalecidos nesse processo, ao invés de continuar focando em políticas intervencionistas e auxílio emergencial.

Levando isso em consideração, fica mais evidente que o RDH de 1994 reflete não apenas uma alteração do que é segurança, mas também da compreensão do que é desenvolvimento dentro deste primeiro estágio, como classificam Tadjbakhsh e Chenoy (2007). O Relatório possuía como tema central o desenvolvimento humano sustentável, ao afirmar que esse é o desenvolvimento que prioriza a população pobre ao ampliar suas escolhas e oportunidades enquanto empodera pessoas. A segurança humana foi vista como parte da busca pelo desenvolvimento humano, uma vez que o desenvolvimento centrado nas pessoas é necessário para conquistar a paz, direitos humanos, proteção ambiental e integração social, estabelecendo que “[s]em paz, pode não existir desenvolvimento. Mas sem desenvolvimento, a paz é ameaçada12" (UNDP, 1994: p. iii). Além disso, propunha descobertas de sinais de alerta precoce que poderiam ser utilizados como diplomacia preventiva - essa foi uma alteração solicitada pelo Secretário-Geral Kofi Annan, quando abordou as causas de conflitos e promoção da paz durável - e em prol do desenvolvimento para evitar uma eventual crise.

Dessa forma, a agenda de desenvolvimento propôs tal abordagem para as novas ameaças que surgiam com a nova ordem internacional; dentro de uma lógica das Nações Unidas, isso era pensar em diplomacia preventiva como forma de atuação nos anos 1990. Pode-se notar, no Relatório, que diversos analistas haviam tentado estabelecer definições rigorosas para a segurança humana, mas, assim como outros conceitos fundamentais, essa é mais facilmente identificada pela ausência do que pela sua presença e a maior parte das pessoas compreende segurança de forma instintiva, ou seja, um sentimento inerente. Existe, inclusive,

12 “Without peace, there may be no development. But without development, peace is threatened." (UNDP, 1994: p. iii) 
no RDH, uma seção dedicada para "Segurança humana - como as pessoas a veem $^{13}$ ”, onde são incorporadas citações de indivíduos de diversas nacionalidades definindo segurança, e.g, aluna da quarta série de Gana: “Eu me sentirei segura quando eu souber que eu posso andar nas ruas à noite sem ser estuprada14" (UNDP, 1994: p. 22). O Relatório afirma que:

[s] egurança humana deve ter dois aspectos principais. Isso quer dizer, primeiro, segurança de ameaças crônicas como fome, doença e repressão. E segundo, quer dizer proteção de distúrbios abruptos e danosos da vida diária - seja na casa, no emprego ou em comunidades. Tais ameaças podem existir em todos os níveis de renda e desenvolvimento. ${ }^{15}$ (UNDP, 1994: p. 23)

Ademais, devem sempre existir dois componentes: (i) liberdade de ameaças que prejudicam direitos, segurança à vida das pessoas, estabelecendo a necessidade de ser livre do medo da violência física, do indivíduo ser livre do medo (freedom from fear), de crimes e guerras e (ii) liberdade de necessidades (freedom from want), de acesso à saúde, de acesso econômico e à ambiente estável.

Além disso, o Relatório define sete aspectos como basilares para a abordagem: (1) segurança econômica - renda oriunda de emprego ou assistência social que garanta sobrevivência da pessoa e sua família; (2) segurança alimentar acesso (econômico e físico) a comida básica capaz de garantir o consumo de nutrientes necessário; (3) direito à saúde - ambiente sem propagação de doenças crônicas e com disponibilidade de cuidados médicos; (4) segurança ambiental - ausência de ameaças ambientais e garantias de água potável, ar fresco etc.; (5) segurança pessoal - ausência de violência e ameaças físicas, sejam elas política, de guerra, étnica, de rua, doméstica ou de gênero, abuso de menor ou suicídio; (6) segurança comunitária - segurança dada à pessoa por pertencer a um grupo, e.g., comunidade ou grupo étnico; e (7) segurança política - gozo de direitos humanos básicos, e.g., direito de ir e vir(UNDP 1994).

Por conseguinte, é possível argumentar que existe um esforço pelas “(...) agências da ONU em 'humanizar' o desenvolvimento ao encorajar a mudança dos

13 "Human security - as people see it" (UNDP, 1994: p. 22)

14 "I shall feel secure when 1 know that I can walk the streets at night without being raped." (UNDP, 1994: p. 22)

15 "Human security can be said to have two main aspects. It means, first, safety from such chronic threats as hunger, disease and repression. And second, it means protection from sudden and hurtful disruptions in the patterns of daily life-whether in homes, in jobs or in communities. Such threats can exist at all levels of national income and development." (UNDP, 1994: p. 23) 
agregados nacionais para o foco nas necessidades individuais e empoderamento 16 " (MACFARLANE, KHONG, 2006: p. 139), um processo que ocorre desde a incorporação do conceito de desenvolvimento de Amartya Sen e se acentua a partir do momento em que a abordagem de segurança humana emergiu da agenda do desenvolvimento do PNUD. Tudo isso ocorre em um ambiente pós-Guerra Fria e com o declínio de conflitos entre Estados, no qual florescia o debate sobre a relação entre segurança e novos temas, como privação econômica e qualidade de vida como fontes de instabilidade. Possibilitando a compreensão de que uma ameaça a um indivíduo ou grupo pode ser vista como uma ameaça à segurança internacional.

Cabe destacar que a "concorrência econômica-tecnológica, os desequilíbrios ambientais, a explosão populacional, as migrações internacionais e o narcotráfico" (VILLA, 1999: p. 99) também ocupavam espaço na agenda de segurança no pósGuerra Fria. Outro aspecto fundamental do debate dizia respeito ao tema da saúde, sobretudo em virtude da epidemia de HIV/AIDS na época - a emergência de uma epidemia local pode resultar em um contágio global, através dos sistemas de transportes modernos. Assim, é possível notar que a desterritorialização de transações econômicas e culturais passaram a impactar na autonomia dos Estados e da sociedade internacional, evidenciando a necessidade de atuar de forma cooperativa, conforme ressalta o RDH.

O "empoderamento" era a inclusão mais recente no que se compreendia como desenvolvimento humano; tal inclusão foi feita no RDH de 1993 e prossegue até hoje, corroborando que o empoderamento é essencial dentro do Estado e em mercados não somente devido à melhora da participação popular, mas porque desenvolvimento também quer dizer ajudar e amparar as pessoas para que elas sejam capazes de controlar as suas vidas. Isso foi estendido para a realidade da segurança, como já se afirmava no Relatório do PNUD de 1993:

[o] conceito de segurança deve mudar - de um foco exclusivo em segurança nacional para maior ênfase à segurança das pessoas, da segurança através dos armamentos para segurança para desenvolvimento humano, de segurança territorial para comida, emprego, e segurança ambiental. ${ }^{17}$ (UNDP, 1993: p. 1-2)

16 "UN agencies in "humanizing" development by encouraging the shift from national aggregates to a focus on individual needs and empowerment.” (MACFARLANE, KHONG, 2006: p. 139)

17 "The concept of security must change from an exclusive stress on national security to a much greater stress on people's security, from security through armaments to security through human development, from territorial security to food, employment and environmental security." (UNDP, 1993: p. 1-2) 
O impacto do Relatório de 1994 para o debate sobre desenvolvimento e sobre segurança deve-se ao fato de que, pela primeira vez, segurança foi explicitamente ligada a políticas de desenvolvimento dentro do sistema ONU. Ele recomenda uma transição conceitual profunda de distanciamento da segurança militar ou nuclear e de aproximação entre os dois temas, especialmente ao passo que certos conflitos intraestatais estavam crescendo e que suas origens eram largamente baseadas em disparidades econômicas e privações.

Como qualquer outra concepção de segurança, a segurança humana trata da capacidade de identificar ameaças, de evitá-las sempre que possível e mitigar seus efeitos quando ocorrem. No entanto, seu sentido específico engloba a ideia de que a segurança vai além do mero conceito de segurança física no sentido tradicional, e incorpora a perspectiva de que a vida das pessoas deve ser garantida através de "segurança social" contra distúrbios repentinos (TADJBAKHSH, 2005). Neste mesmo sentido, a teórica Mary Kaldor (2007) define então segurança humana como a defesa dos indivíduos e de suas comunidades ao invés de segurança dos Estados e dos princípios que esclarecem as diferenças relativas às abordagens convencionais da segurança e do desenvolvimento, ressaltando então a primazia dos direitos humanos, autoridade política legítima, multilateralismo e abordagem bottom up e regional. Deve-se ressaltar, entretanto, que não existe uma definição única para segurança humana ${ }^{18}$ e o termo vem sendo referenciado na academia das relações internacionais e de desenvolvimento como ponto de partida de análise, visão de mundo, agenda política ou estrutura política.

De tal modo, é possível argumentar que a ideia de segurança humana é composta de duas partes entendidas como indissociáveis: desenvolvimento e proteção. A primeira reconhece a relevância do desenvolvimento humano e de fontes econômicas para evitar conflitos enquanto a segunda reconhece proteção física como prioridade. Prover segurança humana se traduz em iniciativas para construir um ambiente seguro para o desenvolvimento humano em uma relação de mútua influência. Existe uma aparente disputa entre campos da comunidade da segurança humana que argumentam por ou "primeiro desenvolvimento" ou "primeiro segurança”; no entanto, na perspectiva da segurança humana, as duas posições não são mutuamente exclusivas, segundo MacFarlane e Khong (2006, p. 201).

18 Para maiores discussões sobre a definição da segurança humana, ver, e.g. Security Dialogue. What is Human Security. vol. 35, no. 3, September, 2004. Special Section. Edição especial com a pergunta "O que é segurança humana?”. Para marcar os dez anos da segurança humana, reuniu os 21 acadêmicos que mais haviam expressado sua opinião sobre o termo, que até hoje facilita a localização dos teóricos no debate entre amplo e restrito. 
É necessária cautela para distinguir de forma adequada segurança humana, desenvolvimento humano e direitos humanos, uma vez que todos estão entrelaçados na preocupação direta com a melhoria da natureza das vidas humanas, mas os conceitos possuem distinções entre si. É possível observar que a ideia de segurança humana suplementa a perspectiva expansionista de desenvolvimento humano, que se preocupa diretamente com as pessoas, suas capacidades e oportunidades ao invés de somente com a forma pela qual as mesmas contribuem para o crescimento econômico do Estado.

Deve-se atentar ao que muitas vezes são chamados de "riscos descendentes", por Sen et al.(2003), ou seja, as inseguranças que ameaçam a sobrevivência humana ou sua segurança do cotidiano. São aqueles fatores que colocam em perigo a dignidade natural dos indivíduos, expõem o ser humano à incerteza de doenças e pestes ou sujeitam pessoas vulneráveis a penúrias abruptas relacionadas a quedas econômicas que demandam atenção especial aos perigos da privação repentina de segurança humana - é necessária, então, não somente a proteção em relação a tais perigos, mas também o empoderamento das pessoas para que estas consigam lidar com e, quando possível, superar tais ameaças.

Não existe contradição entre o foco da segurança humana e o objeto da abordagem do desenvolvimento humano, mas a ênfase e as prioridades são distintas. A segurança humana não se preocupa em compreender as capacidades e oportunidades do indivíduo, mas sim se eles estão livres de ameaças e se sua vida está sendo garantida com dignidade, por consequência. O desenvolvimento humano busca o crescimento com igualdade, mas, ao mesmo tempo, não se preocupa com aquele trabalhador deslocado ou o desempregado perene e o que ele pode gerar em termos de ameaças à segurança dele mesmo e da sociedade em que convive, aspecto com o qual a segurança humana se preocupa. Até hoje, o paradigma mais importante para o PNUD é o de desenvolvimento humano.

Tal relação complementar com os direitos humanos é ainda mais nítida. Conforme Sen et al (2003) argumenta, o último conceito é invocado frequentemente em debates políticos contemporâneos e possui uma atratividade profunda na ideia de que toda pessoa, em qualquer lugar do mundo, independente de cidadania ou localização, possui alguns direitos básicos que devem ser respeitados. O que é notório é que segurança é um direito humano em si, conforme previsto no artigo 3 da Declaração Universal dos Direitos Humanos (DUDH): “[t]odas as pessoas têm direito à vida, à liberdade e à segurança pessoal” (OHCHR, 1948) e tal direito é visto como uma obrigação do Estado. Tadjbakshsh, Chenoy (2007, p. 74) ainda 
afirmam que segurança, além de ser um direito fundamental, é um “grau 0” dos direitos humanos, que vem antes mesmo das três diferentes gerações de direitos (direitos políticos; direitos sociais e econômicos e direitos de diferença).

Dessa forma, o comprometimento com direitos humanos demanda que certas liberdades básicas dos indivíduos sejam respeitadas, auxiliadas e melhoradas. Assim, a natureza normativa do conceito dos direitos humanos o deixa em aberto a questões sobre quais liberdades especificamente são cruciais ou mesmo se existe uma hierarquia entre elas sob as quais a sociedade deveria reconhecer, salvaguardar e promover. Nesse sentido, quando liberdades e inseguranças se relacionam e se suplementam existe diálogo entre segurança humana e direitos humanos, uma vez que essa perspectiva de segurança busca libertar indivíduos de inseguranças - liberdade de necessidades (freedom from want), liberdade do medo (freedom from fear) e liberdade para agir por si. Não obstante, é necessário evidenciar que a compreensão do papel do Estado é configurada de forma distinta para ambas as abordagens, uma vez que os direitos humanos outorgam ao Estado o papel de responsável primário ou garantidor dos direitos fundamentais do indivíduo, mantendo uma visão estadocêntrica, até pelo seu caráter normativo; enquanto a segurança humana desconfia do mesmo, vendo-o como uma possível fonte de ameaças.

É possível afirmar, então, que a segurança humana complementa a segurança estatal, aprimora os direitos humanos e fortalece o desenvolvimento humano, conforme faz o relatório da CSH (SEN et al, 2003). Não existem contradições entre segurança humana, desenvolvimento humano e direitos humanos e, sim, complementariedades. Cada conceito foca em aspectos distintos do bem-estar diário do ser humano na busca para que ele tenha direitos fundamentais, seja capaz e livre de ameaças para exercer tais direitos de forma econômica, social e política. Contudo, a definição do RDH para segurança humana é ampla e atores fazem interpretações bastante distintas da mesma, conforme poderemos ver no relatório que será discutido a seguir.

\section{Segurança humana sob o olhar do novo milênio}

Como afirmamos anteriormente, a RSH foi criada para promover o conceito de segurança humana como política e seu objetivo era influenciar a agenda de segurança internacional em 1999. A iniciativa partiu dos governos do Canadá e 
da Noruega (MACFARLANE, KHONG, 2006), sendo composta por ministros das relações exteriores de 13 países que, com encontros anuais, concordaram em buscar iniciativas coordenadas, formais e informais. No primeiro encontro, em Lysøen, o foco da visão da segurança humana era tanto sobre o indivíduo livre do medo (freedom from fear) quanto sobre o indivíduo livre de necessidades (freedom from want), mas os encontros subsequentes ampliaram ou desdobraram a lista de políticas ou objetivos programáticos focalizados na compreensão da segurança humana somente como liberdade do medo (freedom from fear).

É possível notar que a RSH funciona como uma facilitadora. Krause (2014) afirma que ela é uma formadora de agenda na área de proliferação e mau uso de armas leves, bens de conflito e crianças-soldado, sendo vista como uma extensão do grupo informal dos Estados que haviam trabalhado juntos com sucesso no processo de Ottawa sobre minas terrestres antipessoais (KRAUSE, 2014). Desta forma, a RSH abriu espaço para outras iniciativas em termos de formação de rede entre Estados dispostos a defender uma agenda específica, principalmente para a CIISE. Mesmo que não exista uma relação institucional entre ambas, o protagonismo do governo canadense nas duas iniciativas e sua leitura restrita do que era segurança humana são claras. A publicação final é realizada pelo Centro Internacional de Desenvolvimento de Pesquisa ${ }^{19}$, braço do governo canadense que financia pesquisa. Assim, o governo canadense cunha a Responsabilidade de Proteger em 2001, através da discussão da relação entre soberania estatal, intervenção e direito internacional. A Comissão possui como objetivo final produzir um Relatório que busca responder "se e quando é apropriado para estados tomarem ações coercitivas - e particularmente militares - contra outro estado pelo propósito de proteger pessoas em risco neste outro estado"20 (ICISS, 2001: p. vii).

Enquanto na dimensão de desenvolvimento temos o RDH como marco inicial para definir a abordagem, é possível argumentar que o marco inicial da agenda de segurança é o Relatório da CIISE. A Comissão é a reposta da comunidade internacional para as falhas e inações dos anos de 1990 em termos de intervenções humanitárias, ou seja, é a agenda de segurança focando na liberdade do medo (freedom from fear) e buscando compreender de que forma podemos falar do foco no indivíduo em termos de segurança sem ferir a soberania do Estado,

19 Ver https://www.idrc.ca/

20 “ (...) the question of when, if ever, it is appropriate for states to take coercive - and in particular military — action, against another state for the purpose of protecting people at risk in that other state." (ICISS, 2001: p. vii) 
bem como compreender qual é a responsabilidade da comunidade internacional para com esses indivíduos, uma vez que os próprios Estados não estão sendo capazes de suprir suas necessidades básicas e estão eles próprios, muitas vezes, violando direitos.

Contudo, o Relatório olha para a segurança humana através de uma percepção restrita, a da segurança do indivíduo de ameaças físicas somente, e essa é a primeira "definição" ou "contraproposta" que a agenda de segurança faz à definição do RDH. É possível argumentar que a conjuntura histórica dos anos de 1990, aliada à liderança canadense, induziu a discussão focada nas questões da soberania e intervenção humanitária, não permitindo que questões como desenvolvimento, saneamento básico ou empoderamento fossem incorporadas na compreensão de segurança do relatório. A CIISE é criada em setembro de 2000, pelo primeiroministro canadense do período, Jean Chrétien, com um mandato para construir uma compreensão mais ampla do problema de reconciliar intervenção com fins de proteção humana e soberania (ICISS, 2001), focando no desenvolvimento de políticas que buscassem tirar o sistema internacional, principalmente a ONU, da paralisia e erros dos anos de 1990 , a ser debatida e comunicada na $56^{a}$ sessão da AGNU. A Comissão contava também com o apoio de fundações dos EUA (MACFARLANE; KHONG, 2006).

Chefiada por Gareth Evans e Mohamed Sahnoun, a CIISE foi composta por outros 10 acadêmicos, diplomatas e políticos de diversas nacionalidades ${ }^{21}$, que redigiram o relatório de forma unânime. Cabe notar que a própria publicação ressalta que alguns membros gostariam de ter criado critérios mais amplos ou mais específicos e com maior ou menor flexibilidade para intervenção militar fora do escopo do Conselho de Segurança. Como reflexo de tal descompasso, foram constituídos um Conselho Consultivo, um Time de Suporte e um Time de Pesquisa. Além da composição da Comissão, para detalhar a elaboração do Relatório, existe, inclusive, um volume suplementar chamado "Pesquisa, Bibliografia e Background" (ICISS, 2001b), no qual 114 páginas detalham a bibliografia utilizada como base para o relatório como um todo, que contou com o auxílio do professor Neil MacFarlane da Universidade de Oxford, mais uma vez evidenciando que esse é

21 Mohamed Sahnoun (diplomata algeriano) e Gareth Evans (acadêmico e político australiano) são co-presidentes, acompanhados de: Gisèle Côté-Harper (advogada e acadêmica canadense), Lee Hamilton (político norteamericano), Michael Ignatieff (acadêmico e político canadense), Vladimir Lukin (ativista político russo), Klaus Naumann (ex-militar alemão), Cyril Ramaphosa (político, empresário e ativista sul-africano), Fidel Ramos (expresidente filipino), Cornelio Sommaruga (diplomata e advogado suíço), Eduardo Stein (diplomata e político guatemalteco) e Ramesh Thakur (acadêmico indiano). 
um esforço majoritariamente acadêmico, mas, no caso, ao contrário do RDH, com financiamento e suporte estatais 22 .

O Conselho Consultivo é presidido pelo ministro canadense Lloyd Axworthy e composto por personalidades políticas, acadêmicas e diplomáticas de diversas nacionalidades. Ele tinha a função de auxiliar a comissão a embasar o relatório em realidades políticas correntes e assistir na constituição de engajamento necessário para dar seguimento às recomendações do mesmo. O conselho se encontrou presencialmente com a comissão em junho de 2001, enquanto a comissão realizou cinco encontros entre 2000 e 2001 (Ottawa, em novembro de 2000; Maputo, em março de 2001; Nova Deli, em junho de 2001; Wakefield, em agosto de 2001; e Bruxelas, em setembro de 2001). Também existiu um encontro informal da comissão em Genebra em fevereiro de 2001, contando com membros presentes e via conference call, além de múltiplos encontros em pequenos grupos dos membros da comissão, mesas-redondas e consultas (ICISS, 2001).

Buscando enriquecer o conteúdo que deveria compor o relatório e garantir que a comissão ouvisse uma ampla variedade de visões ao longo de seu mandato, aconteceram onze mesas-redondas regionais e consultas nacionais ao redor do mundo, conduzidas entre janeiro e julho de 2001. Pelo menos um dos presidentes da comissão estava sempre presente nessas consultas. Outros membros da comissão incluíam atores governamentais, não governamentais e sociedade civil; universidades, instituições de pesquisa e think tanks. Antes de cada consulta, compartilhou-se entre esses participantes um documento com as principais questões sob a perspectiva da comissão para estimular o debate e participantes específicos foram convidados a preparar contribuições e apresentá-las para que a comissão pudesse utilizar a posteriori esse novo material produzido. Outro participante, em cada uma das mesas-redondas, foi selecionado para produzir um relatório resumido dos procedimentos e resultados de cada mesa.

A mesa-redonda de Santiago, por exemplo, foi presidida por Francisco Rojas Aravena da Faculdad Latinamericana de Ciencias Sociales do Chile e a fala inicial, feita pela ministra das Relações Exteriores do Chile, Maria Soledad Alvear, se referiu a intervenções como questões de vida ou morte, questões estas que as organizações internacionais não estavam sendo capazes de responder de forma apropriada, uma vez que violações e massacres continuavam ocorrendo. Ela

22 Foi financiada por organizações internacionais como Carnegie Corporation of New York, William and Flora Hewlett Foundation e a Simons Foundantion, além de pelo governo canadense, que doou um milhão de dólares e também recebeu contribuições do Reino Unido e Suíça. 
enfatizou, ainda, que a história da América Latina e do Caribe possui uma estrutura doutrinal que se opõe a intervenções unilaterais e favorece o respeito à soberania dos Estados. Por mais que a região confie na Carta da ONU, as decisões do CSNU podem ser bloqueadas pelos interesses de seus membros e assim não responder com a rapidez necessária às situações que demandam intervenção internacional e então ela sugeriu que como salvar vidas deve sempre ser o interesse maior, devemos ser capazes de criar mecanismos novos e originais (ICISS, 2001: p. 370). O documento inicial propunha a ideia de "multilateralismo cooperativo" como base para construir consenso e processo decisório nas questões centrais do sistema internacional, incluindo intervenção humanitária. Tal abordagem seria positiva, prática e baseada em ideais como paz e prosperidade, além de adotar um conceito de segurança mais holístico.

Tal proposta foi bem aceita pelos presentes, que concordaram na necessidade da revisão do conceito de segurança. Porém, não houve consenso sobre qual conceito deveria ser utilizado. O próprio suplemento do relatório afirma: “devido à falta de ferramentas teóricas compreensivas para explicar os fenômenos mais recentes dentro da arena internacional, novos nomes, como 'segurança ambiental', 'segurança cidadã', e 'segurança humana', têm aparecido” (ICISS, 2001: p. 371)23, enquanto outros preferem ampliar o conceito de segurança para incluir novas ameaças, atores e relações de poder. Além disso, sugeriu-se que a própria globalização tornara o conceito de soberania obsoleto, uma vez que as ameaças atuais, novas ou antigas, são de natureza transnacional e, dessa forma, ignoram fronteiras territoriais. Outros pontos discutidos na mesa-redonda foram: (i) quando a intervenção militar externa deve ser considerada e por que, inclusive considerando as prioridades e limiares; (ii) quando não intervir e por que; (iii) o impacto de intervenções militares externas da perspectiva política, econômica e social; e (iv) intervenção “para democracia”.

Briefings regulares também eram realizados nas capitais governamentais, bem como nas missões diplomáticas em Ottawa, Genebra e Nova Iorque em junho de 2001, nas quais representantes da comissão se encontravam com representantes de diversas missões permanentes, bem como com o Secretário-Geral Kofi Annan e os principais membros do secretariado da ONU (ICISS, 2001). Paralelamente

23 "Because of a lack of comprehensive theoretical tools to explain the most recent phenomena within the international arena, new tag names, such as "environmental security," "citizen security," and "human security," have appeared. Others have preferred to broaden the traditional concept of international security to include new threats, actors, and power relationships." (ICISS, 2001: p. 371) 
às consultas, montou-se um programa de pesquisa extensivo para sustentar o trabalho da comissão e complementar os esforços também das mesas-redondas e das discussões que ocorreram na ONU, em níveis regionais e em demais fóruns. Assim, foi criado um time de pesquisa internacional, chefiado pelo americano Thomas Weiss ${ }^{24}$ e o zimbabuense Stanlak e Samkange 25 (ICISS, 2001). Weiss e seu consultor de pesquisa canadense, Don Hubert, assumiram a responsabilidade primária de produzir artigos de pesquisa para o volume suplementar, enquanto Samkange era o rapporteur e assistia a comissão na redação dos esboços do seu relatório. O objetivo por trás dessa iniciativa foi disseminar o conceito criado pelo relatório.

A Responsabilidade de Proteger é o conceito criado pelo relatório ao comparar intervenção humanitária com segurança humana, mas sua ênfase reside na primeira. Ele consiste basicamente na noção de que o Estado possui a responsabilidade de proteger a sua própria população de riscos de conflitos e repressão estatal ou colapso, enquanto a comunidade internacional possui a responsabilidade de intervir quando Estados são incapazes ou não querem assegurar seus nacionais e assegurar a liberdade do medo (freedom from fear) (ICISS, 2001;ALMQVIST, 2005).O conceito vem da mesma linha de pensamento da segurança humana ao referir-se aos direitos fundamentais do ser humano. Em gerenciamento de conflito, esses dois conceitos enfatizam a necessidade de focar novamente no indivíduo quando compreendemos segurança internacional e suas ameaças pela comunidade internacional. É importante mencionar que a comissão, ao longo do relatório, afirma, repetidamente, que acredita que intervenções devem ocorrer, mas somente em caso de violações massivas de direitos humanos, que sejam derivadas de conflitos internos, insurgência, repressão ou fraqueza do Estado ou quando o Estado é incapaz ou relutante por algum motivo em solucionar o problema. Contudo, a Responsabilidade de Proteger não abarca somente intervenção, uma vez que a comissão estabelece que a responsabilidade da comunidade internacional frente às questões humanitárias está dividida em três etapas: responsabilidade de prevenir, responsabilidade de reagir e responsabilidade de reconstruir (ICISS, 2001).

A compreensão da responsabilidade de prevenir é um desdobramento de algo que já vinha ocorrendo dentro das próprias Nações Unidas, cujas resoluções já tomavam uma posição de prevenção de conflitos. O relatório, então, enfatiza

24 É professor da City University of New York e também co-diretor do Projeto de História Intelectual da ONU.

25 Advogado e ex-redator de discursos do Secretário-Geral Boutros Boutros-Ghali. 
que para uma base sólida para prevenção de conflitos é necessário um forte comprometimento estatal a fim de assegurar o bem-estar dos cidadãos e a boa governança. Os avisos antecipados dos governos nacionais à ONU são tidos como soluções pelo documento, buscando deixar clara a situação do país.

De todo modo, a própria publicação já previa dificuldades, uma vez que o próprio Estado poderia não ser claro com tais dados, levantando uma questão de credibilidade. Ainda dependemos de organizações não governamentais como Anistia Internacional, Human Rights Watch, agências especializadas da ONU e outras que tem presença em campo para divulgação de dados de violações de direitos humanos para trabalhar na prevenção e aviso antecipados. Em convergência com a segurança humana, o relatório faz menção à perda de vidas de forma direta e arraigada. Perdas de vida de forma direta seriam por questões envolvendo liberdade do medo (freedom from fear) e as arraigadas envolvendo questões referentes à liberdade de necessidades (freedom from want), tais como pobreza, distribuição desigual de recursos e repressão política. A prevenção pode ser realizada através de fortalecimento institucional, podendo envolver inclusive o Secretário-Geral na busca de maior estabilidade econômica por meio da mediação de escritórios internacionais, por exemplo.

Já a responsabilidade de reagir entra em ação quando a prevenção falha e o Estado não é capaz ou se ausenta, pelos motivos mais variados, a acabar com as violações massivas aos direitos humanos. As medidas de reação, intervenção ou coerção podem ser econômicas, políticas ou jurídicas e, como último recurso ou casos extremos, a ação militar é considerada. Assim, o próprio relatório afirma que a intervenção militar a favor dos direitos humanos é uma medida extraordinária e excepcional e, sendo assim, ela deve respeitar os seguintes requisitos: causa justa $^{26}$, intenção correta, último recurso, medidas proporcionais e perspectivas razoáveis (ICISS, 2001).

O Relatório também discute os desdobramentos que vão além da prevenção e reação propriamente ditas, trazendo a questão da responsabilidade de reconstruir. Então, se ocorrer intervenção militar e houver incapacidade do Estado em prover mínima proteção aos seus nacionais, é necessário que exista um comprometimento da comunidade internacional na reconstrução das estruturas, incluindo meios de

26 Quando existe intenção ou perda de vida em grande escala, seja com intenções genocidas ou não, podendo partir do Estado como uma ação deliberada ou não, ou de sua incapacidade, negligência ou fragilidade; ou quando existe intenção ou "limpeza étnica" em larga escala, através de expulsão forçada, assassinato, atos de terror ou estupro (ICISS, 2001: p. 32). 
promover uma paz duradoura a partir da boa governança e do desenvolvimento sustentável (ICISS, 2001). Isso retoma a lógica da liberdade de necessidades (freedom from want) da segurança humana, uma vez que aqui a preocupação não é somente a segurança física do cidadão, mas seu bem-estar como um todo. O documento reconhece que, historicamente, a questão da responsabilidade da reconstrução não recebia o devido foco e era mal administrada, uma vez que a saída das forças que intervinham não era planejada e sim descompromissada. Além disso, existe um componente importante na construção da paz que consiste em colocar antigos oponentes lado a lado, para trabalhar na construção da paz e reconstruir seu país, buscando criar emprego, moradia e novas condições de vida, o que muitas vezes depende de um mediador internacional. Em suma, o relatório enfatiza três áreas onde a reconstrução deve focar: segurança, justiça e desenvolvimento econômico.

Na elaboração desse relatório, também é possível observar uma participação significativa de pesquisadores e debate acadêmico na construção do que seria a segurança humana ou mesmo da forma pela qual a intervenção humanitária seria "reinterpretada" aos olhos da segurança humana, o que resultou na Responsabilidade de Proteger. A participação e envolvimento dos Estados, organizações internacionais e atores da sociedade civil acontecem de maneira mais contundente, em uma verdadeira tentativa de construir uma rede de advocacy transnacional. Mesmo assim, é possível notar que a interpretação do governo canadense do que é segurança humana, restrita e focada na ausência de ameaças física (freedom from fear), acaba por influenciar o conteúdo final do mesmo de forma latente - por mais que exista um notável esforço na composição da variedade de nacionalidades entre os especialistas envolvidos no processo.

A primeira "contraproposta" da agenda da segurança ao conceito de segurança humana surge então ainda influenciada de forma significativa pela segurança tradicional, com foco no Estado como provedor de segurança e nas ameaças físicas somente, praticamente ignorando a ampliação dos temas de segurança que vinha ocorrendo desde o final da Guerra Fria. Como consequência, discutem somente quando e como atores internacionais devem intervir para proteger indivíduos em casos nos quais seus governos são incapazes de oferecer proteção ou são os próprios violadores de direitos. É possível argumentar que o segundo estágio da segurança humana perde o foco do conceito e retorna para a concepção tradicional da segurança. 


\section{Conclusões}

Neste artigo, analisamos o percurso da segurança humana a partir do RDH, em 1994,para o seu segundo estágio de construção, quando foi reavivado em uma interpretação distinta no relatório da CIISE. O primeiro surge de uma perspectiva mais holística de segurança humana, que incluía a percepção que o indivíduo deveria estar livre de necessidades (freedom from want) e livre do medo (freedom from fear) de forma indivisível e indissociável para que a segurança fosse conquistada. Já o segundo se ocupa quase exclusivamente da visão do indivíduo livre do medo (freedom from fear), ou seja, de ameaças à sua integridade física. Tal fato dissocia termos que deveriam ser, teoricamente, indissociáveis - o desenvolvimento e a proteção. Essa dissociação ocorre através de temas mais tradicionais da agenda de segurança, ao travar o debate de intervenção humanitária com segurança humana no relatório do CIISE, fazendo com que a relevância seja a ação militar e não o empoderamento e o foco no indivíduo. Além do gap temporal significativo entre os dois relatórios (1994 e 2001), cada um assume um compromisso e uma pretensão de responder aos mesmos desafios, mas focando ou compreendendo as ameaças de forma distintas.

É relevante notar que ambos são resultados de esforços de atores governamentais e não governamentais, mas que contam também com uma significativa participação de pesquisas acadêmicas e que a estrutura de confecção desses documentos possui funcionamento, objetivo e desenho bastante semelhantes às pesquisas acadêmicas, mesmo que tenham suas estruturas alocadas dentro de organismos internacionais. Os dois documentos são exemplos do esforço em aproximar a teoria da prática, para que seja possível responder às oscilações constantes da dinâmica política internacional de forma razoavelmente contundente e embasada.

Contudo, a partir da grande diferença temporal e da falta de debate entre a primeira definição de segurança humana no RDH e a definição proposta pelos acadêmicos e Estados patrocinadores do relatório CIISE, houve uma divisão da agenda do conceito de segurança humana em duas vertentes: (1) uma visão mais ampla de segurança e desenvolvimento e (2) uma visão vinculada à proteção de civis em conflitos armados. Essa dicotomia, inclusive, fica clara na apropriação feita pelos Estados quando aplicam a segurança humana: enquanto o Japão tem a sua visão de segurança humana focada na primeira vertente, o Canadá tem a sua focada na segunda. Assim, na agenda de desenvolvimento, temos o RDH como marco inicial para definir a abordagem, porém o marco inicial da agenda de 
segurança, no que tange uma proposta ou mesmo resposta ao primeiro relatório, é o CIISE. A partir desses elementos, foi possível notar baixa convergência entre ambos relatórios com relação à construção da segurança humana, o que acaba comprometendo sua aplicabilidade prática - conforme exemplo dos países citados acima. Tal divisão faz com que a segurança humana permaneça sem definição clara, uma vez que cada ator escolhe a vertente que melhor se encaixa às suas necessidades e interesses.

\section{Referências}

ALMQVIST, Jessica. Building a New Role for the United Nations: the Responsibility to Protect. A Roundtable Discussion on the Recommendations on UN Reform Madrid: FRIDE, 2005.

BUZAN, Barry. A Reductionist, Idealistic Notion that Adds Little Analytical Value. Security Dialogue, Vol 35, Issue 3, 2004: 369-370. Disponível em: http://journals.sagepub. com/doi/abs/10.1177/096701060403500326. Último Acesso em: nov. 2016.

BURGESS, Peter; et al. What is Human Security. Security Dialogue. vol. 35, no. 3, September, 2004. Disponível em: http://journals.sagepub.com/toc/sdib/35/3 Último Acesso em: nov. 2016.

HAMPSON, Fen Osler; et al. Madness in the Multitude: Human Security and World Disorder. Ottawa: Oxford University Press, 2002.

HSU. "HS Handbook.” HS Handbook. 2009. http://www.un.org/humansecurity/sites/ www.un.org.humansecurity/files/human_security_in_theory_and_practice_english.pdf. Último Acesso em: nov. 2016.

ICISS. The Responsibility to Protect. Ottawa: International Development Research Centre, 2001. ICISSb. The Responsability to Protect - Research, Bibliography, Background. Ottawa: International Development Research Centre, 2001.

JAHAN, Selim. Entrevista: Selim Jahan. Diretor do Escritório do Relatório do Desenvolvimento Humano, jun. 2016. Entrevista concedida a Raquel Maria de Almeida Rocha.

KALDOR, Mary. Human Security. Cambridge: Polity, 2007.

KRAUSE. Critical perspectives on human security. In MARTIN, Mary; OWEN, Taylor (edits.) Routledge Handbook on Human Security, New York: Routledge, 2014, p. 76-93. MACFARLANE, Neil; KHONG, Yuen. Human Security and the UN A Critical History. Bloomington: Indiana University Press, 2006.

MARTIN, Mary; OWEN, Taylor. Routledge Handbook on Human Security,. Oxford: Routledge, 2015. 
MARTIN, Mary; OWEN, Taylor. The second generation of human security: lessons from the UN and EU experience. International Affairs. Volume 86, Issue 1, January 2010: p. 211-224. Disponível em: http://onlinelibrary.wiley.com/doi/10.1111/j.14682346.2010.00876.x/abstract Último Acesso em: nov. 2016.

MCRAE, Rob; HUBERT, Don. Human Security and the New Diplomacy: Protecting People, Promoting Peace. Montreal: McGill-Queen's University Press, 2001.

MUKHOPADHYAY, Tanni. Entrevista: Tanni Mukhopadhyay. Senior Researcher and Policy Specialist, jun. 2016. Entrevista concedida a Raquel Maria de Almeida Rocha.

NEF, Jorge. Human Security and Mutual Vulnerability The Global Economy of Development and Underdevelopment. Ottawa: International Development Research Centre, 1999. NEWMAN, Edward. Critical human security studies. Review of International Studies. Volume 36 Issue 1, 2010: p. 77-94. Disponível em: https://www.cambridge.org/core/ journals/review-of-international-studies/article/critical-human-security-studies/5F 1FD24C399B41FC77A5A1E677365AE5 Último acesso em: mai. 2016

OHCHR. Convention on the Rights of the Child. 1989. Disponível em: http://www.ohchr. org/Documents/ProfessionalInterest/crc.pdf Último Acesso em: jan. 2016.

OHCHR. Convention on the Elimination of All Forms of Discrimination against Women. 1979. Disponível em: http://www.ohchr.org/Documents/ProfessionalInterest/cedaw. pdf Último Acesso em: jan. 2016.

OHCHR. Declaração Universal dos Direitos Humanos. 1948. Disponível em: http://www. ohchr.org/EN/UDHR/Documents/UDHR_Translations/por.pdf Último Acesso em: nov. 2016.

OWEN, Taylor. The Critique That Doesn't Bite: A Response to David Chandler's 'Human Security: The Dog that Didn't Bark'. Security Dialogue. Vol 39, Issue 4, 2008: p. 445. Disponível em: http://journals.sagepub.com/doi/abs/10.1177/0967010608094038?j ournalCode = sdib Último Acesso em: dez. 2016.

PARIS, R. Human Security: Paradigm Shift or Hot Air? International Security, vol. 26, n.2, 2001, p. 87-102. Disponível em: http://aix1.uottawa.ca/ rparis/Paris.2001. IS.Human\%20Security.pdf Último Acesso em: dez. 2016.

ROTBERG, Robert. "Failed States, Collapsed States, Weak States: Causes and Indicators.” In State Failure and State Weakness in a Time of Terror, by R ROTBERG, 1-25. Whashington: Brookings Institution Press, 2003.

SEN, Amartya; et al. Human Security Now. Comission on Human Security Report. New York: Comission on Human Security, 2003.

SEN, Amartya. Development as freedom. 1st ed. New York: Oxford University Press, 1999. TADJBAKHSH, Shahrbanou; CHENOY, Anuradha. Human Security Concepts and Implications. Abingdon: Routledge, 2007. 
TADJBAKHSH, Shahrbanou. "Human Security: Concepts and Implications with an application to Post-Intervention Challenges in Afghanistan.”Lés Études du CERI No 117-118, 2005. Disponível em: http://www.sciencespo.fr/ceri/sites/sciencespo. fr.ceri/files/etude117_118.pdf Último acesso em: nov. 2015.

UL HAQ, Mahbub. Reflections on Human Development. New York: Oxford University Press, 1995.

UN. A more secure world: our shared responsibility. 2004. Disponível em: http://www. un.org/en/peacebuilding/pdf/historical/hlp_more_secure_world.pdf Último Acesso em: 08/2016.

UN. General Assembly. A/RES/57/264. 30 January 2003. Disponível em: https://documentsdds-ny.un.org/doc/UNDOC/GEN/N02/556/72/PDF/N0255672.pdf?OpenElement Último acesso em: 01/2016.

UN. Comission on Human Security. Human Security Now. New York: 2003. Disponível em: http://www.un.org/humansecurity/sites/www.un.org.humansecurity/files/ chs_final_report_-_english.pdf. Último Acesso em: ago. 2016.

UN. Supplement to An Agenda for Peace. 1995.

UN. The responsibility of the Security Council in the maintenance of international peace and security. New York: UN, 1992.

UN. Convention on the Prevention and Punishment of the Crime of Genocide. 1948. Disponível em: https://treaties.un.org/doc/publication/unts/volume\% 2078/volume78-i-1021-english.pdf Último acesso em: jan. 2016.

UNCHR. The State of The World's Refugees 1997: A Humanitarian Agenda. Disponível em: http://www.unhcr.org/publications/sowr/4a4c72719/state-worlds-refugees1997-humanitarian-agenda.html Último acesso em: ago. 2016.

UNCHR. Convention and Protocol Relating to the Status of Refugees. 1951. Disponível em: http://www.unhcr.org/3b66c2aa10.pdf Último acesso em: jan. 2016.

UNDP. The Human Development Report. The Human Development Reports Office.New York: UN, 2015.

UNDP. Human Development Report 2014 Sustaining Human Progress: Reducing Vulnerabilities and Building Resilience. New York: PBM Graphics, 2014.

UNDP. Human Development Report.The Human Development Reports Office.New York: UN, 2011.

UNDP. Human Development Report. The Human Development Reports Office.New New York: UN, 2006.

UNDP. Human Development Report. An Agenda for the Social Summit. Oxford: Oxford University Press. 1994. Disponível em: http://hdr.undp. org/en/media/hdr_1994_ en_overview.pdf. Último Acesso em: mar. 2016. 
UNDP. Human Development Report 1993: People's participation. New York, 1993.

UNIC. ABC das Nações Unidas. Rio de Janeiro: UNIC RIO, 2009.

UNOCHA. Human Security at the UN - Human Security Unit. [s/d]. Disponível em: http://unocha.org/humansecurity/about-human-security/human-security-un Último Acesso em: ago. 2016.

VILLA, R. “A segurança global multidimensional.” Lua Nova, 1999: 99-119.

WILLIAMS, Paul. Security Studies: An introduction. New York: Routledge, 2008. 